\title{
What is Driving the EU Burden-Sharing Agreement: Efficiency or Equity?
}

\author{
Per-Olov Marklund ${ }^{\mathrm{a}}$ and Eva Samakovlis ${ }^{\mathrm{b}, *}$ \\ ${ }^{a}$ Department of Economics, Umeå University, SE-90187 Umeå, Sweden \\ ${ }^{\mathrm{b}}$ National Institute of Economic Research, Box 3116, SE-10362 Stockholm, Sweden
}

\begin{abstract}
Under the Kyoto Protocol the European Union agreed to reduce emissions of greenhouse gases by 8 percent. The Burden-Sharing Agreement (BSA) redistributes the reduction target among the member states. The purpose of this paper is to evaluate the BSA. To analyze if cost-efficiency were considered, marginal abatement costs are first calculated based on an estimation of the directional output distance function using country production data for 1990-2000. Marginal abatement costs, together with equity indicators are then regressed on the emission change targets. The main conclusion is that both efficiency and equity were important aspects considered in the settlement.
\end{abstract}

JEL classification: C61, D63, D72, L51, Q53

Keywords: burden-sharing, cost-efficiency, directional output distance function, equity.

*Corresponding author. Tel.: +46-8-4535917; fax: +46-8- 4535980, eva.samakovlis@konj.se 


\section{Introduction}

In 1992 over 150 states signed the United Nations Framework Convention on Climate Change (UN-FCCC), which objective is to stabilize greenhouse gas concentrations. The quantification of emission limits, reduction objectives and policies to meet these objectives were settled in Kyoto. This resulted in the adaptation of the Kyoto Protocol in December 1997. Under the Protocol the European Union (EU) committed itself to reducing the emissions of 6 greenhouse gases (GHGs) by 8 percent during the period 2008-2012, in comparison with the levels in 1990. It was agreed that the EU could redistribute its assigned GHG reduction target among the member states as long as the outcome amounted to an overall reduction of at least 8 percent. The problem of how the burden of climate policy should be allocated across countries is one of the most challenging issues in climate negotiations and will largely determine the allocation of abatement costs.

The Climate Convention gave no clear guidelines on how to redistribute, but emphasized the importance of equity and efficiency. ${ }^{1}$ Article 3.1 says that parties should protect the climate system on the basis of equity. Equity is not defined, however according to Article 4.2a: "differences in parties starting points and approaches, economic structures and resource bases, need to maintain strong and sustainable economic growth, available technologies, and other individual circumstances, as well as the need for equitable contributions" should be taken into account in the settlement of reduction targets. Furthermore, Article 3.3 states that policies and measures to deal with climate change should be cost-effective to ensure global benefits at the lowest possible cost. Which national circumstances that should be considered to promote 'equity' and how, were discussed in the country negotiations that preceded the settlement.

Several comprehensive approaches have been launched to address the issue of differentiation of mitigation commitments, among those are; multi-stage, per capita convergence, Triptych, and multi-sector convergence. ${ }^{2}$ The results of the Triptych study (Phylipsen et al., 1998), commissioned by the Dutch Presidency of the EU,

\footnotetext{
${ }^{1}$ Unlike efficiency, no universal consensus exists on the best definition of equity. Key principles of equity in international climate negotiations have been defined by, for example, Ringius et al. (2002) and Rose et al. (1998). In this paper, equity refers to distributional justice of the European redistribution of the 8 percent GHG reduction target.

${ }^{2}$ For an explanation of these approaches, see Sijm et al. (2001).
} 
served as an advisory document and was claimed to influence the final agreement for EU (Blok et al., 1997; Ringius, 1997; Barker et al., 2001). The Triptych study suggests that emissions are 'equitably' redistributed among the member states if national circumstances such as population size and growth, standard of living, economic structure, energy efficiency in power generation, and climate are taken into account. How to actually redistribute was agreed in 1998, and is referred to as the Burden-Sharing Agreement (BSA) (e.g., The Commission of the European Communities, 2000). This agreement lays down differentiated emission limits for each Member State with the aim to ensuring that the EU meets its overall 8 percent reduction commitment under the Protocol. Limits are expressed in terms of percentages by which Member States must reduce, or in some cases may hold or increase, their emissions compared with the base year level (1990). The BSA was reaffirmed by joint ratification of the Kyoto Protocol on May 31 2002, where it became binding international law. The individual states' shares of EU emissions and the BSA figures are given in Table 1.

Since efficiency and equity often are conflicting criteria, the purpose of this paper is to analyze which aspects finally influenced the settlement of the BSA. The equity hypotheses tested refer to whether the national circumstances pointed out by the Triptych study influenced the BSA. In particular, if poorer member states were given a lighter environmental burden. The efficiency criterion focuses on the costeffectiveness of the allocation of abatement resources between the EU Member States. Specifically, the hypothesis tested is whether higher marginal abatement costs (MACs) of GHGs contributed to lighter emission requirements, and vice versa. As a first step, MACs of GHGs are estimated for each EU Member State, using aggregate production data for the period 1990-2000. A shadow pricing model originating from Färe et al. $(2002,2005)$ will be used. The model is founded on production theory where the technology is represented by the directional output distance function, from which the MACs are derived. To test the cost-efficiency and equity hypotheses, the BSA emission changes are regressed on the estimated MACs together with variables capturing differences in national circumstances, suggested by the Climate Convention and the Triptych study.

Many economic analyses, following the adaptation of the Kyoto Protocol, have focused on analyzing the market for GHGs emission trading. The main conclusion of these studies is that trading improves cost-efficiency, lowering the cost of 
implementing the Protocol. ${ }^{3}$ Overviews of such studies are provided in the IPCC Third Assessment Report of Working Group III "Mitigation" by Metz et al. (2001), and in the special issue of the Energy Journal, edited by Weyant and Hill (1999). Even if the permit allocation does not affect cost efficiency, it can be interpreted as a lump sum redistribution instrument to pursue equity objectives. Equity and efficiency issues have been analyzed focusing on the distribution of carbon dioxide tradable emission permits (see e.g., Larsen and Shah, 1994; Nilsson, 2004; Rose et al., 1998; Shiell, 2003).

At least in the first trading period 2005 to 2007 of the European Union GHG Emission Trading Scheme (EU ETS), only carbon dioxide emission intensive industries will be involved in the trade. In order to reach the BSA countries need to adopt other measures to control emissions in sectors not covered by the EU ETS. Given the large sums that have to be spent on abatement, it is important that the overall reductions made are cost efficient. An analysis of the BSA will reveal if the European reduction of GHGs is cost efficient and equitable. To our knowledge, only few analyses question the BSA; a welfare analysis by Böhringer et al. (2002) translates the BSA into welfare impacts using a static computable general equilibrium (CGE) model of the EU. These impacts are composed of substitution effects and cross-country income effects triggered by the imposition of carbon emission constraints. Their results indicate that the BSA does not result in an equitable outcome in welfare terms. In a similar analysis by Eyckmans et al. (2002) a welfare analysis is made using a CGE model for Europe. To visualize the efficiency-equity trade-off, implicit welfare weights are calculated making the BSA a welfare optimum for the EU. The conclusion drawn from their simulations is that even if richer member states have been assigned relatively high abatement efforts and poorer ones are allowed to emit more, this differentiation does not go far enough. ${ }^{4}$ Babiker et al. (2003) analyze to what extent the welfare costs associated with the BSA implementation depend on sectoral allocation of emission rights. They find that equalizing MACs across sectors greatly reduces the burden but that

\footnotetext{
3 In a competitive permit market profit maximizing incentives will make pollutants undertake abatement measures until the marginal cost of the last ton avoided equals the market price of the pollution permits.

${ }^{4}$ A disadvantage with both these analyses is that they have to make projections on future economic development, in particular energy efficiency improvements. These projections will drive their results and if not accurate will be a source of error for the analysis.
} 
pre-existing tax distortions can make other allocations preferable. In addition, Viguier et al. (2003) quantify the economic impacts of the Kyoto commitment when each EU member state individually meets a $\mathrm{CO}_{2}$ emission target.

The paper is structured as follows. In Section 2 a theoretical framework for computing MACs is provided. Section 3 gives the empirical model. First, the directional output distance functional form and the techniques to estimate this form is provided. Then, a model for analyzing the BSA is suggested. In Section 4 the data are described, and in Section 5 the empirical results are given. Finally, Section 6 offers summary and conclusions.

\section{Theory}

\subsection{The directional output distance function}

To calculate MACs of undesirable outputs a shadow-pricing model originating from Färe et al. $(2002,2005)$ will be used. ${ }^{5}$ It bases on the directional ouput distance function which is used to characterize the production technology. The distance function is a measure of technical efficiency in production. The technical efficiency rate indicates how efficient resources are used.

Formally, let $y=\left(y_{1}, \ldots, y_{M}\right) \in \mathfrak{R}_{+}^{M}$ and $b=\left(b_{1}, \ldots, b_{J}\right) \in \mathfrak{R}_{+}^{J}$ be vectors of good and undesirable outputs, respectively, and let $x=\left(x_{1}, \ldots, x_{N}\right) \in \mathfrak{R}_{+}^{N}$ be a vector of inputs. The technology of reference is the output possibilities set, $P(x)$, which for a given vector of inputs denotes all technically feasible output vectors. This output set is assumed to be convex and compact with $P(0)=\{0,0\}$. Furthermore, inputs and good outputs are assumed to be freely disposable and undesirable outputs only weakly disposable. Finally, good outputs are assumed to be null-joint with the undesirable outputs. This means that good outputs cannot be produced without producing undesirable outputs. The directional output distance function is defined on the output possibilities set, $P(x)$, as

\footnotetext{
${ }^{5}$ Marklund (2003) provides an application of this model to the Swedish pulp industry, together with a thorough overview of the development of the estimation of undesirable output shadow prices.
} 
$D(x, y, b ; g)=\max _{\beta}\left\{\beta:\left(y+\beta \cdot g_{y}, b-\beta \cdot g_{b}\right) \in P(x)\right\}$

which then inherits its properties from $P(x)$. The solution, $\beta^{*}$, gives the maximum expansion and contraction of good outputs and undesirable outputs, respectively. The vector $g=\left(g_{y},-g_{b}\right)$ specifies in which direction an output vector, $(y, b) \in P(x)$, is scaled so as to reach the boundary of the output set at $\left(y+\beta^{*} \cdot g_{y}, b-\beta^{*} \cdot g_{b}\right) \in P(x)$, where $\beta^{*}=D(x, y, b ; g)$. This means that the producer becomes more technically efficient when simultaneously increasing good outputs and decreasing undesirable outputs. The distance function takes the value of zero for technically efficient output vectors on the boundary of $P(x)$, whereas positive values apply to inefficient output vectors below the boundary. The higher the value the more inefficient is the output vector. Finally, the directional output distance function satisfies the translation property

$$
D\left(x, y+\alpha \cdot g_{y}, b-\alpha \cdot g_{b} ; g\right)=D(x, y, b ; g)-\alpha
$$

where $\alpha$ is a positive scalar. It is the additive analogue of the multiplicative homogeneity property of the Shephard output distance function (Färe et al., 2005). ${ }^{6}$

\subsection{The shadow-pricing model}

When deriving the output shadow-pricing model from the directional output distance function, the duality between the distance function and the revenue function is exploited. Let $p=\left(p_{1}, \ldots, p_{M}\right) \in \mathfrak{R}_{+}^{M}$ and $q=\left(q_{1}, \ldots, q_{J}\right) \in \mathfrak{R}_{+}^{J}$ represent absolute prices of good and undesirable outputs, respectively. Färe et al. (2005) showed that relative shadow prices of undesirable outputs, in terms of the m:th good output, can be calculated from

\footnotetext{
${ }^{6}$ The translation property states that if good output is expanded by $\alpha g_{y}$ and bad output is contracted by $\alpha g_{b}$, then the value of the distance function will be more efficient with the amount $\alpha$.
} 


$$
\frac{q_{j}}{p_{m}}=-\left(\frac{\partial D(x, y, b ; g)}{\partial b_{j}} / \frac{\partial D(x, y, b ; g)}{\partial y_{m}}\right), \quad j=1, \ldots, J
$$

This is the marginal rate of transformation between the $j: t h$ undesirable output and the $m: t h$ good output, $M R T_{j m}$, and where $\partial D(\cdot) / \partial y_{m}<0$ and $\partial D(\cdot) / \partial b_{j} \geq 0$. The MAC is then measured in terms of decreased production of $y_{m}$, which has to be met when reducing $b_{j}$ marginally, once all technical inefficiency has been eliminated.

The shadow-pricing model is illustrated in Figure 1. The output possibility set is given by $P(x)$ and the technically inefficient output vector $(y, b)$ is produced. Given the directional vector, $g=(1,-1)$, the directional output distance function in (1) scales $(y, b)$ until it reaches the boundary of $P(x)$ at $A$. This particular point has a supporting hyper plane interpreted as a shadow price relation, $q^{*}-p^{*}$, which counts for $(y, b)$, and can be calculated using the formula in (3). By definition nonnegative MACs of bad outputs correspond to tangents on the boundary where the slope is nonnegative.

\section{The empirical model}

\subsection{The directional output distance function}

Following Färe et al. (2005), the directional output distance function is parameterized using a (additive) quadratic flexible functional form. In our case, with one good output, one bad output, and three inputs, the particular form is

$$
\begin{aligned}
D^{k t}\left(x^{k t}, y^{k t}, b^{k t} ; g\right) & =\alpha_{0}+\sum_{n=1}^{3} \alpha_{n} x_{n}^{k t}+\beta_{1} y_{1}^{k t}+\gamma_{1} b_{1}^{k t} \\
& +\frac{1}{2} \sum_{n=1}^{3} \sum_{n^{\prime}=1}^{3} \alpha_{n n^{\prime}} x_{n}^{k t} x_{n^{\prime}}^{k t}+\sum_{n=1}^{3} \delta_{n 1} x_{n}^{k t} y_{1}^{k t}+\sum_{n=1}^{3} \eta_{n 1} x_{n}^{k t} b_{1}^{k t} \\
& +\frac{1}{2} \beta_{11} y_{1}^{k t} y_{1}^{k t}+\mu_{11} y_{1}^{k t} b_{1}^{k t} \\
& +\frac{1}{2} \gamma_{11} b_{1}^{k t} b_{1}^{k t} \\
& +\kappa_{k}+\tau_{t}
\end{aligned}
$$


where $\kappa$ and $\tau$ are parameters representing country and time specific effects, respectively. The function is computed using both a linear programming technique (LP) and a Corrected Ordinary Least Squares (COLS) technique. ${ }^{7,8}$ How the functions are computed with the different techniques is described in the Appendix. As in Färe et al. (2005) the directional vector $g=(1,-1)$, where 1 refers to $g_{y}$ and -1 refers to $-\mathrm{g}_{b}$, is chosen (see Figure 1). This choice of direction is consistent with environmental regulations, which require reduction in bad outputs.

\subsection{Analysing the BSA}

The Climate Convention emphasizes that developed countries are mainly responsible for historical and current emissions of GHGs, and that developing countries must be allowed less demanding constraints so that their social and development needs can be fulfilled (Phylipsen et al., 1998). Criticism against the BSA claims that equity has been overlooked and that the assigned emission reduction targets are against the Cohesion Member States, i.e., Spain, Portugal, Ireland, and Greece (Dessai, 1999). ${ }^{9}$ The purpose of this paper is to evaluate the BSA from both an equity and efficiency perspective. In order to accomplish that, the following regression model is suggested

$$
B S A^{k}=\phi+\zeta \mathrm{Z}^{k t}+\omega M A C^{k t}+\rho W^{k t}+v^{k t}
$$

where $k=1, \ldots, K$ denotes the EU Member States and $t=1, \ldots, T$ denotes the years. The dependent variable, $B S A^{k}$, is the countries percentage reduction or increase in GHG emissions assigned by the Burden Sharing Agreement. ${ }^{10}$ The vector $Z^{k t}$ contains variables of national circumstances that are suggested by the Climate Convention and recommended in the Triptych study to promote equity. ${ }^{11}$ The

\footnotetext{
${ }^{7}$ The LP estimating procedure is also adopted in Marklund (2003).

${ }^{8}$ For an application of COLS to the Shephard output distance function, see Lovell et al. (1994).

9 These countries are eligible for support from the European Cohesion Fund, which aims to encourage greater economic and social cohesion and uniformity of living standards between member states.

${ }^{10}$ See Burden sharing in Table 1.

${ }^{11}$ The Triptych study covers only energy related $\mathrm{CO}_{2}$ emissions, while the BSA covers total country emissions of an additional 5 GHGs (methane, nitrous oxide, hydrofluorocarbons, perfluorocarbons,
} 
elements of the vector $Z$ will be described in Section 4. Furthermore, by including the marginal abatement cost estimate, $M A C^{k t}$, obtained by applying the shadowpricing model in (3), a cost-efficiency hypothesis test is made possible. However, in this model the $M A C^{k t}$ variable is a generated regressor that is stochastic and, therefore, not fixed in repeated samples. In order to correct for any heteroscedasticity that may occur, the expression in (9) is regressed as a White estimator, giving heteroscedastic-consistent standard errors. Furthermore, vector $W^{k t}$ contains other variables that possibly influenced the BSA, and these variables will also be described in Section 4 . The last term on the right-hand side, $v^{k t}$, is an error term that is uncorrelated with all other right-hand side variables and uncorrelated in time and across countries. The parameters to be estimated are $\phi, \zeta$, $\omega$, and $\rho$. As the model in (9) is specified it is assumed that the BSA, which was settled in 1998, is based on historical information and expectations about the nearest future, covering the period 1990-2000.

\section{Data}

The directional output distance function is estimated using aggregated annual data for the EU Member States provided by AMECO and Eurostat. ${ }^{12}$ AMECO is a macro economic data bank available at the European Commission's DirectorateGeneral for Economic and Financial Affairs. More specifically, the countries included are Austria, Belgium, Denmark, Finland, France, Germany, Greece, Ireland, Italy, Luxembourg, Netherlands, Portugal, Spain, Sweden, and United Kingdom for the period 1990-2000. This results in an unbalanced panel of 156 observations, since some countries lacked data for a few years. To produce the good output GDP, $y_{1}$, each country is assumed to use three inputs; energy, $x_{1}$, labor, $x_{2}$, and capital, $x_{3}$. One undesirable output, $b_{1}$, i.e., a by-product from producing GDP, is modeled as a compound of 6 greenhouse gases, GHGs. ${ }^{13}$ Energy is the country's

and sulphur hexafluoride). Emissions of these gases are to be weighted according to their 100-year global warming potential.

${ }^{12}$ Distance functions have mostly been applied to plant level data. For an example of an application of the Shephard output distance function to aggregated country level data, see Färe et al. (1994).

${ }^{13}$ These are; carbon dioxide $\left(\mathrm{CO}_{2}\right)$, methane $\left(\mathrm{CH}_{4}\right)$, nitrous oxide $\left(\mathrm{N}_{2} \mathrm{O}\right)$, and industrial halogenated gases: hydrofluorocarbons (HFC), perfluorocarbons (PFC), and sulphur hexafluoride (SF6). 
final energy consumption measured in giga joule (GJ). Labor is total employment, measured in number of workers, and capital is the net capital stock. Both capital and GDP are measured in 1995 constant prices in 1000 Euro. Data on GHGs are total national emissions measured in tons. This is consistent with the Kyoto Protocol where emission allowances should be specified in number of tons of $\mathrm{CO}_{2}$ equivalent that can be emitted. Descriptive statistics for the inputs and outputs are provided in Tables 2 and 3. Finally, when estimating the distance function, all variables were transformed into per capita terms.

To test the cost-efficiency and equity hypotheses, the BSA emission change variable (from Table 1) is regressed on the MAC variable, and variables representing national circumstances in accordance with the model in (9). The Climate Convention states that national circumstances should be taken into account in the negotiations. The Triptych study (Phylipsen et al., 1998) tried to clarify which variables were important and how they should be accounted for. ${ }^{14}$ The suggested circumstances relevant to promote equity were; standard of living, economic structure, energy efficiency, fuel mix in power generation, climate, and population size and growth. These circumstances constitute the basis for the elements of the vector $Z$ in equation (9). Standard of living is approximated with mean Consumption expenditure per household in 1000 Euro for the year $1994 .{ }^{15}$ The Climate Convention emphasizes that developed countries are mainly responsible for historical and current emissions and should therefore make the largest reductions. According to UN-FCCC Article 4.7, economic and social development and poverty eradication are the first and overriding priorities of the developing country parties. This also applies to the EU Cohesion Member states. Therefore, to promote equity, countries with currently low consumption expenditures should be given lighter environmental burdens.

There are differences in economic structure between countries resulting in differences in energy consumption and, therefore, GHG emissions. To capture such differences the relative size of the energy intensive manufacturing industry, Industry gross value added as a share of GDP, is included. Energy intense sectors

\footnotetext{
${ }^{14}$ Claimed to influence the final agreement for EU (Blok et al., 1997; Ringius, 1997; Barker et al., 2001).

${ }^{15}$ The Triptych study used GDP per capita, however since GDP per capita is used in our estimation of MACs we chose to use another proxy for standard of living.
} 
will consume more energy than other sectors even if energy is used efficiently. It is, therefore, not necessarily fair that countries with comparatively large energy intense sectors would be given more stringent emission targets. Therefore, differences between emission reduction potential by lowering energy use should be accounted for when promoting equity. The extent of energy intensity in this sector is approximated by the industry's final energy consumption divided by its produced gross value added, measured in GJ per billions of Euro, and called Industry energy intensity.

The fuel mix consumed by the country also influences the emission reductions potential. ${ }^{16}$ To incorporate this particular circumstance, the variables Oil share, Electricity share, and Renewable share are added. They measure the share of crude oil and petroleum product, the share of electricity, and the share of renewable energy in final energy consumption, respectively.

The different climate of the European countries results in varying heating/cooling needs. It has been argued that heating needs of the coldest countries were taken into account although the cooling needs of the warmest countries were foreseen (Dessai, 1999). To see if climate affected the BSA, Temperature, the deviation of the countries' average temperatures from the EU average temperature, for the period 1961-1990, is included. The temperature data are collected from the data set TYN CY 1.1 in Mitchell (2003).

Finally, the population size circumstance is accounted for by including the variable Population, measured in millions of inhabitants. The absolute demand for goods and services are largely determined by the population size, e.g., for personal transport, residential space heating/cooling, etc., and, therefore, results in a certain correlation between emissions and population size.

In addition, a set of other variables that potentially could have influenced the BSA settlement was added. These variables were represented by vector $W$ in equation (9). Forests can be used as carbon sinks and absorb $\mathrm{CO}_{2}$ from the atmosphere. To see if forest resources were taken into account, Forest land is included as millions of ha wooded area in 1995. Furthermore, since older cars are less energy efficient and have dirtier exhaust, the average age of the total number of

\footnotetext{
${ }^{16}$ The Triptych study suggests the fuel mix in power generation. However, in this paper, the fuel mix consumed at the country level is approximated.
} 
cars, Car age, was included. Descriptive statistics for all these variables are provided in Table 4.

\section{Results}

As in Färe et al. (2005) the directional output distance function is estimated on mean normalized input and output data. From Section 2 we know that for the distance function to be well-behaved it needs to be nonnegative and the constraints of null-jointness, monotonicity, symmetry, and the translation property need to hold. These constraints are imposed in LP. In COLS the properties of nonnegativity, translation, and symmetry are imposed, but monotonicity and nulljointness are tested for afterwards. The COLS estimation shows that null-jointness is satisfied for 119 observations (76 percent). Monotonicity in outputs is fully satisfied for GDP, and for 150 observations (96 percent) in the case of GHGs. ${ }^{17}$ The parameters of the LP and COLS estimated distance functions are provided in Table 5.

Table 6 includes arithmetic averages for the mean normalized technical efficiency scores, $C D$ and $D$, together with potential output changes. ${ }^{18}$ For a hypothetical country that during 1990-2000 used the sample mean of inputs to produce the sample mean of outputs, the LP and COLS estimated values of the distance function, 0.002 and 0.004 , respectively, indicate that the production is not technically output efficient. In the LP model the average inefficiency ranges from 0.01 to 0.05 and for the whole sample the average is 0.02 , implying that the countries could on average, without changing resources or developing technology, increase GDP with $19.08 * 0.02=0.38$ thousand Euro per capita and reduce GHGs with $12.42 * 0.02=0.25$ tons per capita. ${ }^{19}$ Due to the COLS estimating procedure, the average inefficiency is the same for all countries and for the whole sample, i.e., 0.06 , indicating that countries could on average increase GDP with 1.14 thousand Euro per capita and reduce GHGs with 0.75 tons per capita.

\footnotetext{
${ }^{17}$ Monotonicity in GHGs is not satisfied for 6 Luxembourg observations, resulting in negative MACs. For these observations the derivative w.r.t. GHGs, is set to zero, implying zero MACs.

${ }^{18}$ The technical efficiency scores, $C D$ and $D$, in Table 6 measures the deviations from the estimated technological frontier.

19 Since the distance function is estimated on mean normalized data, where the mean quantity of GDP is 19.08 thousand Euro per capita and GHGs is 12.42 tons per capita.
} 
The GDP and GHGs quantity changes are further compared to actual quantities produced in each country. The COLS procedure indicates that the Cohesion Member States have a larger potential in percentages to increase their efficiency, holding input quantities and technologies fixed. For instance, Greece could increase GDP and decrease GHGs with 12.89 and 6.82 per cent respectively. ${ }^{20}$

Computed MACs for GHGs in terms of GDP, according to equation (3), are presented in Table $7 .^{21}$ The LP model indicates that to reduce GHG emissions with one ton, the hypothetical 'at mean' country has to reduce GDP with 510 Euro. In COLS the corresponding figure is 490 Euro $^{22}$, with a confidence interval of $199-$ 797 Euro/ton at the 5 percent significance level. ${ }^{23}$ Results from other analyses determining MAC of carbon dioxide vary widely depending on the methodology. Most of them use MAC curves derived from detailed technological or macroeconomic models. The OECD (1998) report, presents results from different analyses on the cost of implementing the Kyoto Protocol that show large variance in MACs ranging from $\$ 78$ to $\$ 773$ for Europe. ${ }^{24}$ Critical to the results of these analyses is the definition of the underlying baseline scenario ${ }^{25}$, and the differences in model parameters. ${ }^{26}$ The advantage with our setup is that no such assumptions have to be made. A disadvantage is that the data, due to limitations, is aggregated representing national MACs for the whole economy. As a consequence, the derived MACs are not comparable to permit prices derived from analyses only including the industries involved in the trade. Such analyses usually exclude household and transport sectors where it is expectedly comparatively more expensive to reduce carbon dioxide. $^{27}$

${ }^{20}$ The differences in percentage efficiency in Table 6 are artefacts of different levels of GDP and GHG.

${ }^{21}$ The MAC figures refer to slopes on the estimated technological frontier.

22 The sample averages are somewhat higher, 570 for the LP model and 670 for the COLS model.

23 As the COLS procedure generate variance estimates, the Delta test was applied to create a confidence interval for the MAC estimate. The test is thoroughly described in, e.g., Greene (2002).

${ }^{24}$ The models and the associated MACs were: G-Cubed 167 \$/ton, Poles 140 \$/ton, GTEM 773 \$/ton, WorldScan 78 \$/ton, GREEN 196 \$/ton and AIM 214 \$/ton.

${ }^{25}$ Scenario assumptions involving high population and GDP growth rates, a relatively clean fuel mix and high energy costs will lead to higher cost estimates.

${ }^{26}$ Especially important is the assumptions regarding the ability to substitute labor and capital for energy and the inter-fuel substitution elasticity. The higher these substitution possibilities are assumed to be, the lower the MACs (OECD, 1998).

${ }^{27}$ See for example Springer (2003) who gathers results from 25 models of the market for tradable greenhouse gas emission permits. The spectrum of prices ranges from 1 to 22 USD per ton $\mathrm{CO}_{2}$. 
Our results reveal that MACs vary considerably between countries. For instance, Portugal faces a relatively high MAC and Luxembourg a relatively low MAC. One explanation for this could be that the functional form used is only a local approximation, and that countries that differ significantly from the rest may be assigned extreme MACs. The MACs also differ between LP and COLS, this is partly due to that null-jointness and monotonicity are not fulfilled for all observations in COLS. ${ }^{28,29}$

To evaluate the BSA from an efficiency-equity perspective, hypothesis tests are performed given the regression model in (9). The resulting estimates are provided in Table 8 . The estimated coefficient for the MAC variable, $\omega$, allows for a costefficiency hypothesis test to determine whether the MAC served as a positive determinant to the GHG change targets redistributed by the BSA. The results show that it did, irrespective of technique used to estimate the MACs. The member states with higher MACs were assigned easier emission change requirements, and vice versa, indicating that efficiency was considered.

For the equity hypotheses tests, a negative sign of the estimated coefficient for Consumption expenditure, $\zeta_{1}$, indicates that equity was considered in the BSA negotiations, since countries with lower standards of living were assigned easier emission requirements. In fact, this variable alone explains 67 percent of the variation in BSA. This result favours the Cohesion Member States who were assigned lighter environmental burdens due to low expenditures per household, and contradicts Dessai (1999) who claims that equity has been overlooked. The fact that the results indicate both efficiency and equity considerations contradicts the general opinion that there necessarily is an efficiency-equity trade-off. Dessai (1999) also claims that a so called heating degree-day correction was made to benefit northern countries, but a cooling correction was omitted which weighed heavily against southern member states and worked against equity. The Temperature coefficient, $\zeta_{7}$, shows the contrary, that warmer countries were given easier emission requirements. Furthermore, the negative coefficient of Industry gross value added

\footnotetext{
${ }^{28}$ A test where the LP estimating procedure is conducted without imposing these constraints reveal a closer confirmity of MACs between these methods (see e.g., Marklund, 2004).

${ }^{29}$ It is not obvious which technique to prefer. In LP it becomes fairly simple to impose theoretical assumptions. There is then, a priori, a consistency between the theoretical and empirical parts of the methodology. The COLS methodology used, does not force the distance function to satisfy null-jointness and monotonicity. In consequence certain observations violate these assumptions.
} 
as a share of $G D P, \zeta_{2}$, indicates that countries with relatively large energy intensive manufacturing industries was punished with heavier burdens, which is not in favour of equity. The Industry energy intensity coefficient, $\zeta_{3}$, is insignificant in the COLS specification, and significantly positive in the LP specification, indicating that countries with relatively larger energy use in the energy intense industry were assigned easier emission requirements, which works against equity. The coefficients, $\zeta_{4}-\zeta_{6}$, for the fuel mix indicators, i.e., Oil share, Electricity share and Renewable share, work in favour of equity. Finally, the negative coefficient of Population, $\zeta_{8}$, indicates that countries with larger population were given heavier burdens, which do not support equity .

Regarding the additional variables, the positive coefficient for Forest land, $\rho_{1}$, indicates that countries with wide forest areas were assigned lighter environmental burdens, recognizing the carbon sink function. Furthermore, the Car age coefficient, $\rho_{2}$, indicates that countries with comparatively old cars were considered able to make larger emission reductions. ${ }^{30}$

The directional vector plays a role in determining shadow prices for interior output bundles of the output possibilities set, $P(x)$, in (1). As in Färe et al. (2005) projections to the technological frontier are made in a direction that increases good output and decreases bad output. A direction which would keep bad output constant and increasing good output, which corresponds to the directional vector, $g=(1,0)$, would be expected to lead to lower shadow prices of bad output. However, this does not necessarily mean that our conclusions from evaluating the BSA do not hold. To check whether these conclusions are sensitive to direction of projecting inferior output bundles to the frontier, the procedure in (9) is also accomplished given that

\footnotetext{
${ }^{30}$ If multicollinearity is present the estimates may be afflicted with uncertainty, reflected by lower $t$ values due to larger variances. Then, even if the OLS estimator is unbiased, large variance may result in parameter estimates showing the wrong sign. To reduce multicollinearity, and to check whether it influenced the conclusions, a reduced model was estimated excluding Oil share and Electricity share. This means that each circumstance that the Triptych study considered important for equity was approximated with one single variable. In the reduced model, $t$-values for 6 out of 9 parameter estimates become larger and no estimate alters sign. Therefore, the conclusion drawn from the original model, that efficiency did not rule out equity is strenghtened (the reduced model results can be obtained from the authors on request).
} 
the distance function in (1) is estimated conditional on $g=(1,0)$, using linear programming. As it turns out, in general our conclusions do not alter. ${ }^{31}$

\section{Summary and conclusions}

This paper provides an analysis of the European Union (EU) greenhouse gases (GHGs) policy. The Climate Convention was signed in 1992, with the objective to stabilize concentration of GHGs. Explicit objectives and measures to be taken were settled in Kyoto, resulting in the adoption of the Kyoto Protocol in December 1997. Under the Protocol, EU committed itself to reducing the emission of 6 GHGs by 8 percent during 2008-2012, in comparison with the 1990 level. It was further agreed that EU could redistribute the assigned GHGs reduction target among the member states. The Climate Convention gave no clear guidelines on how to accomplish the redistribution, but emphasized the importance of equity and cost-efficiency. Which national circumstances that should be considered were much discussed. The Triptych study (Phylipsen et al., 1998) served as an advisory document and suggested that emissions are 'equitably' redistributed if national circumstances such as population size and growth, standard of living, economic structure, energy efficiency in power generation, and climate are taken into account. However, how to actually redistribute GHG emission changes was agreed politically among the EU Member States in 1998, and is referred to as the Burden-Sharing Agreement (BSA). It resulted in a differentiation of the EU GHGs emission reduction target, where half of the member states reduce their emissions while the rest stabilize, or even are allowed to increase, emissions. The BSA was reaffirmed by joint ratification of the Kyoto Protocol in 2002, where it became binding international law. In light of these facts, the main purpose of this paper is to evaluate the BSA from both an economical and a political perspective performing hypothesis tests of whether cost-efficiency and equity were considered in the BSA settlements.

Variables used to perform the equity tests are chosen on the basis of the Triptych study and are readily available. However, the marginal abatement cost

\footnotetext{
31 The only coefficient that alters sign is the one for industry energy intensity. These results can be obtained from the authors on request.
} 
(MAC) variable, used to test the cost-efficiency hypothesis, must be computed. As a first step, aggregate production data are used to compute MACs for each of the 15 EU Member States in each year of the period 1990-2000. A shadow-pricing model approach, suggested by Färe et al. (2002, 2005), which includes estimation of the directional output distance function, is adopted for that purpose. In a second step, the hypothesis tests are made possible by regressing the BSA emission change figures on the MAC and equity variables, together with other variables that potentially had an influence on the BSA.

A general conclusion drawn is that efficiency did not rule out equity, and vice versa, when settling the BSA. The results show that efficiency arguments had an influence on burden-sharing. EU Member States with higher MACs of GHGs were assigned easier emission change requirements compared to states with lower MACs. Also equity arguments were important in the settlement. The results show that countries with lower standard of living, in terms of consumption, were assigned easier emission change requirements. 


\section{Acknowledgement}

Earlier drafts of this paper have been presented in seminars at Umeå University and at the Swedish National Institute of Economic Research whose participants we would like to thank for comments. In particular, we are grateful to Thomas Aronsson, Chuan-Zhong Li, Jonas Nordström and three anonymous referees for their helpful comments and suggestions. We also thank Marie Hammarstedt for her editorial help. The usual disclaimer applies. 


\section{References}

Aigner, D.J., and S. J. Chu, 1968, On estimating the industry production function, American Economic Review 58, 826-839.

Babiker, M. H., P. Criqui, A. D. Ellerman, J. M. Reilly and L. L. Viguier, 2003, Assessing the impact of carbon tax differentiation in the European Union, Environmental Modeling and Assessment 8, 187-197.

Barker, T., T. Kram, S. Oberthür and M. Voogt, 2001, The role of EU internal policies in implementing greenhouse gas mitigation options to achieve Kyoto targets, International Environmental Agreements: Politics, Law and Economics $1,243-265$.

Blok, K., G. J. M. Phylipsen and J. W. Bode, 1997, The Triptique approach. Burden differentiation of $\mathrm{CO}_{2}$ emission reduction among European Union Member States. Zeist: Discussion paper for the informal workshop for the European Union Ad Hoc Group on Climate, 16-17 January 1997.

Böhringer, C., T. F. Rutherford and G. W. Harrison, 2002, Sharing the burden of carbon abatement in the European Union, in: Böhringer, C. and A. Löschel (eds.), Empirical Modelling of the Economy and the Environment (ZEW Economic Studies, Heidelberg).

Commission of the European Communities, 1999, Preparing for implementation of the Kyoto protocol, $\operatorname{COM}(1999) 230$ final (Commission Communication to the Council and the Parliament).

Commission of the European Communities, 2000, Green paper on greenhouse gas emissions trading within the European Union, $\operatorname{COM}(2000) 87$ final (presented by the Commission).

Dessai, S., 1999, A critique of the EU burden sharing agreement, Change 47, 13-16.

Eyckmans, J., J. Cornillie and D. Van Regemorter, 2002, Efficiency and equity in the EU burden sharing agreement, Working paper series no 2000-02, Energy, Transport and Environment, Katholieke Universiteit Leuven.

Färe, R., S. Grosskopf, D-W. Noh and W. Weber, 2005, Characteristics of a polluting technology: theory and practice, Journal of Econometrics 126, 469492. 
Färe, R., S. Grosskopf and W. L. Weber, 2002, Shadow prices and pollution costs in U.S. agriculture, paper presented at the Second World Congress of Environmental and Resource Economists 2002, Monterey, California.

Färe, R., S. Grosskopf, M. Norris and Z. Zhang, 1994, Productivity growth, technical progress and efficiency change in industrial countries, The American Economic Review 84, 66-83.

Greene, W., 1993, The econometric approach to efficiency analysis, in: Fried, H. O., C. A. K. Lovell and S. S. Schmidt (eds.), The measurement of productive efficiency (Oxford University Press).

Greene, W., 2002, Econometric analysis, Fifth Edition (Prentice Hall).

Larsen, B. and A. Shah, 1994, Global tradable carbon permits: Participation incentives and transfers, Oxford Economic Papers 46, 841-856.

Lovell, C. A. K., S. Richardson, P. Travers and L. Wood, 1994, Resources and functionings: A new view of inequality in Australia, in Eichhorn, W. (eds.), Models and measurement of welfare and inequality (Springer-Verlag).

Marklund, P-O., 2003, Analyzing interplant marginal abatement cost differences: A directional output distance function approach, Umeå Economic Studies, No 618, Umeå University.

Marklund, P-O., 2004, Essays on productive efficiency, shadow prices and human capital, Umeå Economic Studies, No 621, Umeå University.

Metz, B., O. Davidson, R. Swart and J. Pan, 2001, Climate change 2001: Mitigation, Contribution of working group III to the third assessment report of the Intergovernmental Panel on Climate Change (IPCC).

Mitchell, T. D., 2003, A comprehensive set of climate scenarios for Europe and the globe, Manuscript, Tyndall Centre for Climate Change Research.

Nilsson, C., 2004, Studies in environmental economics: Numerical analysis of greenhouse gas policies, Dissertation, Stockholm School of Economics, Sweden.

OECD, 1998, Economic modelling of climate change, OECD Workshop Report, Held at OECD Head quarters, 17-18 September, 1998.

Phylipsen, G. J. M., J. W. Bode, K. Blok, H. Merkus and B. Metz, 1998, A Triptych sectoral approach to burden differentiation: GHG emissions in the European bubble, Energy Policy 26(12), 929-943.

Ringius, L., 1997, Differentiation, leaders and fairness. CICERO Report 1997:8, Oslo: CICERO. 
Ringius, L., A. Torvanger and A. Underdal, 2002, Burden sharing and fairness principles in international climate policy, International Environmental Agreements: Politics, Law and Economics 2, 1-22.

Rose, A., B. Stevens, J. Edmonds and M. Marshall, 1998, International equity and differentiation in global warming policy: An application to tradable emission permits, Environmental and Resource Economics 12, 25-51.

Shiell, L., 2003, Equity and efficiency in international markets for pollution permits, Journal of Environmental Economics and Management 46, 38-51.

Sijm, J., J. Jansen and A. Torvanger, 2001, Differentiation of mitigation commitments: The multi-sector convergence approach, Climate Policy 1, 481497.

Springer, U., 2003, The market for tradable GHG permits under the Kyoto protocol: A survey of model studies, Energy Economics 25(5), 527-551.

Viguier, L. L., M. H. Babiker, and J. M. Reilly, 2003, The costs of the Kyoto protocol in the European Union, Energy Policy 31, 459-481.

Weyant, J. P. and J. Hill, 1999, The costs of the Kyoto protocol, a multi-model evaluation, The Energy Journal (special issue). 


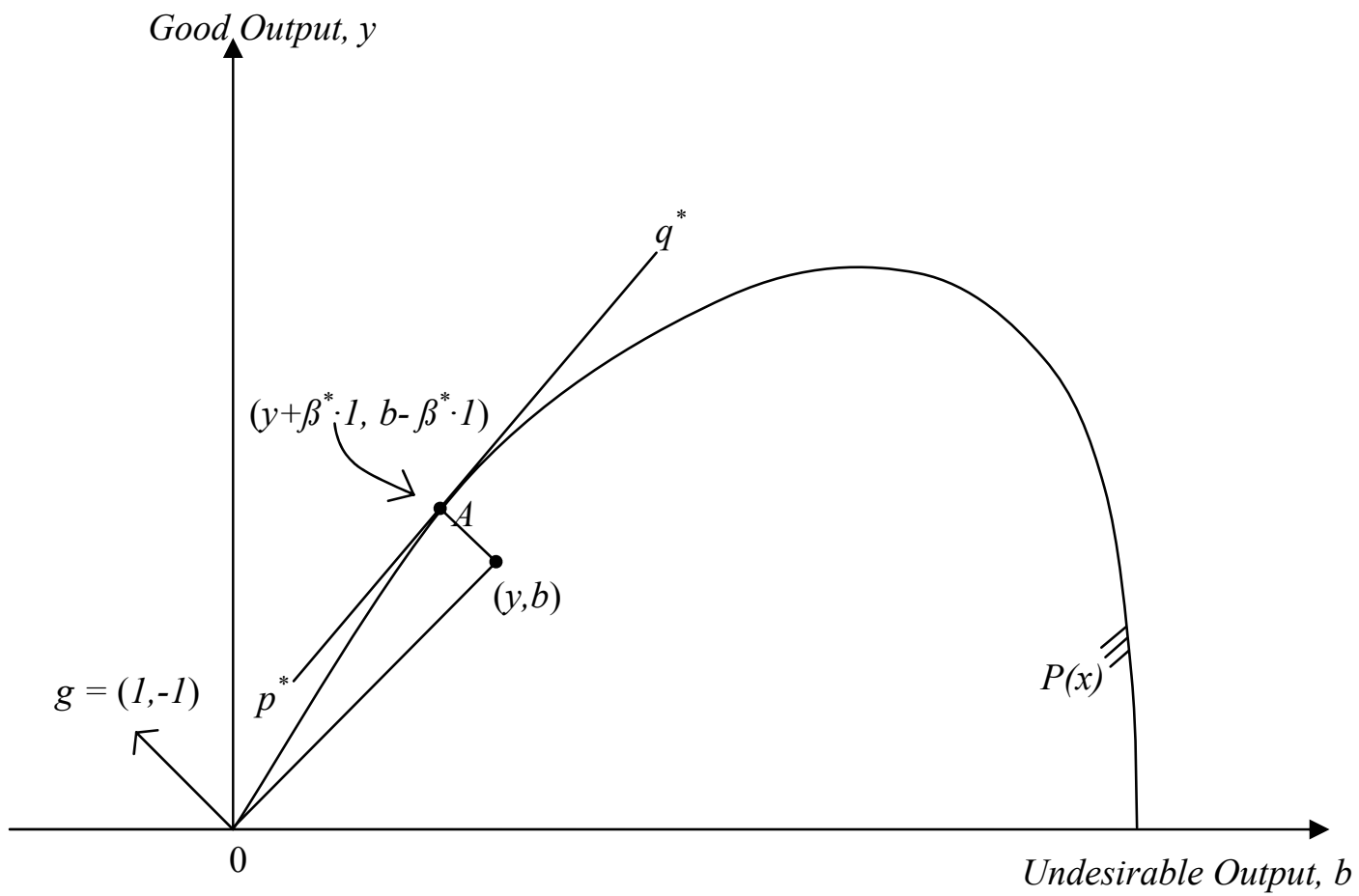

Figure 1 The shadow-pricing model 
Table 1 Greenhouse gas $\left(\mathrm{CO}_{2}+\mathrm{CH}_{4}+\mathrm{N}_{2} \mathrm{O}\right)$ emissions in the EU

\begin{tabular}{|l|c|c|c|c|}
\hline Country & $\begin{array}{c}\text { Share of EU } \\
\text { emissions in } \\
\mathbf{1 9 9 0}\end{array}$ & $\begin{array}{c}\text { Emissions in } \\
\mathbf{1 9 9 0} \text { in Mt eq } \\
\mathbf{C O}_{\mathbf{2}}\end{array}$ & $\begin{array}{c}\text { Burden } \\
\text { sharing } \\
\text { (BSA) }\end{array}$ & $\begin{array}{c}\text { Burden sharing } \\
\text { in Mt eq CO }\end{array}$ \\
\hline Austria & 1.7 & 74 & -13.0 & 64 \\
\hline Belgium & 3.2 & 139 & -7.5 & 129 \\
\hline Denmark & 1.7 & 72 & -21.0 & 57 \\
\hline Finland & 1.7 & 73 & 0.0 & 73 \\
\hline France & 14.7 & 637 & 0.0 & 637 \\
\hline Germany & 27.7 & 1201 & -21.0 & 949 \\
\hline Greece & 2.4 & 104 & 25.0 & 130 \\
\hline Ireland & 1.3 & 57 & 13.0 & 64 \\
\hline Italy & 12.5 & 542 & -6.5 & 506 \\
\hline Luxembourg & 0.3 & 14 & -28.0 & 10 \\
\hline Netherlands & 4.8 & 208 & -6.0 & 196 \\
\hline Portugal & 1.6 & 69 & 27.0 & 87 \\
\hline Spain & 7.0 & 301 & 15.0 & 347 \\
\hline Sweden & 1.6 & 69 & 4.0 & 72 \\
\hline U.K. & 17.9 & 775 & -12.5 & 678 \\
\hline Total EU & 100.0 & 4334 & -8.0 & 3998 \\
\hline Enissa & & & & \\
\hline
\end{tabular}

*Emission limits for each Member State with the aim of ensuring that the EU meets its overall 8 percent reduction commitment under the Protocol. The limits are expressed in terms of percentages by which Member States must reduce, or in some cases may hold or increase, their emission compared with the base year level (1990). Source: Annex 1 of Commission of the European Communities (1999) 230 final of 19.05.1999. 
Table 2 Descriptive statistics per year for variables in the output distance function; mean and standard deviations (in parentheses)

\begin{tabular}{|c|c|c|c|c|c|}
\hline \multirow[t]{2}{*}{ Year } & \multicolumn{5}{|c|}{ Variable } \\
\hline & $y_{1}$ & $b_{1}$ & $x_{1}$ & $x_{2}$ & $x_{3}$ \\
\hline 1990 & $\begin{array}{l}17.14 \\
(6.79)\end{array}$ & $\begin{array}{l}13.00 \\
(5.78)\end{array}$ & $\begin{array}{l}125.60 \\
(84.58)\end{array}$ & $\begin{array}{c}0.42 \\
(0.07)\end{array}$ & $\begin{array}{c}48.63 \\
(17.34)\end{array}$ \\
\hline 1991 & $\begin{array}{l}17.31 \\
(7.06)\end{array}$ & $\begin{array}{l}13.35 \\
(6.02)\end{array}$ & $\begin{array}{l}129.26 \\
(88.99)\end{array}$ & $\begin{array}{c}0.42 \\
(0.07)\end{array}$ & $\begin{array}{c}49.55 \\
(17.31)\end{array}$ \\
\hline 1992 & $\begin{array}{l}17.72 \\
(6.90)\end{array}$ & $\begin{array}{l}13.11 \\
(5.49)\end{array}$ & $\begin{array}{l}127.60 \\
(83.56)\end{array}$ & $\begin{array}{c}0.42 \\
(0.06)\end{array}$ & $\begin{array}{c}52.17 \\
(17.94)\end{array}$ \\
\hline 1993 & $\begin{array}{l}17.43 \\
(6.83)\end{array}$ & $\begin{array}{l}12.69 \\
(5.46)\end{array}$ & $\begin{array}{l}125.52 \\
(81.78)\end{array}$ & $\begin{array}{c}0.40 \\
(0.06)\end{array}$ & $\begin{array}{c}52.17 \\
(17.23)\end{array}$ \\
\hline 1994 & $\begin{array}{l}18.21 \\
(6.87)\end{array}$ & $\begin{array}{l}12.87 \\
(5.97)\end{array}$ & $\begin{array}{l}124.15 \\
(76.19)\end{array}$ & $\begin{array}{c}0.40 \\
(0.05)\end{array}$ & $\begin{array}{c}53.88 \\
(17.16)\end{array}$ \\
\hline 1995 & $\begin{array}{r}18.63 \\
(6.78) \\
\end{array}$ & $\begin{array}{l}12.08 \\
(3.45) \\
\end{array}$ & $\begin{array}{r}122.44 \\
(64.68) \\
\end{array}$ & $\begin{array}{c}0.41 \\
(0.05) \\
\end{array}$ & $\begin{array}{c}54.62 \\
(17.26) \\
\end{array}$ \\
\hline 1996 & $\begin{array}{l}19.03 \\
(6.86) \\
\end{array}$ & $\begin{array}{l}12.45 \\
(3.73) \\
\end{array}$ & $\begin{array}{l}126.72 \\
(64.92) \\
\end{array}$ & $\begin{array}{c}0.41 \\
(0.05) \\
\end{array}$ & $\begin{array}{r}55.46 \\
(17.36) \\
\end{array}$ \\
\hline 1997 & $\begin{array}{l}19.71 \\
(7.17)\end{array}$ & $\begin{array}{l}12.06 \\
(3.22)\end{array}$ & $\begin{array}{l}126.34 \\
(63.51)\end{array}$ & $\begin{array}{c}0.41 \\
(0.05)\end{array}$ & $\begin{array}{c}56.49 \\
(17.51)\end{array}$ \\
\hline 1998 & $\begin{array}{l}20.43 \\
(7.54)\end{array}$ & $\begin{array}{l}11.92 \\
(2.94)\end{array}$ & $\begin{array}{l}127.57 \\
(61.37)\end{array}$ & $\begin{array}{c}0.42 \\
(0.05)\end{array}$ & $\begin{array}{c}57.72 \\
(17.68)\end{array}$ \\
\hline 1999 & $\begin{array}{l}21.14 \\
(7.82) \\
\end{array}$ & $\begin{array}{l}11.81 \\
(2.80) \\
\end{array}$ & $\begin{array}{r}128.98 \\
(63.50) \\
\end{array}$ & $\begin{array}{c}0.43 \\
(0.05) \\
\end{array}$ & $\begin{array}{c}59.09 \\
(17.85) \\
\end{array}$ \\
\hline 2000 & $\begin{array}{l}22.03 \\
(8.37)\end{array}$ & $\begin{array}{l}11.74 \\
(2.74)\end{array}$ & $\begin{array}{l}130.28 \\
(66.04)\end{array}$ & $\begin{array}{c}0.43 \\
(0.05) \\
\end{array}$ & $\begin{array}{r}60.47 \\
(18.03) \\
\end{array}$ \\
\hline $1990-2000$ & $\begin{array}{l}19.08 \\
(7.16)\end{array}$ & $\begin{array}{l}12.42 \\
(4.32)\end{array}$ & $\begin{array}{l}126.74 \\
(70.15)\end{array}$ & $\begin{array}{c}0.42 \\
(0.05)\end{array}$ & $\begin{array}{c}54.83 \\
(17.31)\end{array}$ \\
\hline Min & 7.67 & 6.58 & 46.77 & 0.30 & 16.58 \\
\hline $\operatorname{Max}$ & 43.45 & 31.35 & 385.15 & 0.52 & 88.69 \\
\hline
\end{tabular}

$y_{1}=$ GDP, 1000 Euro (1995 constant price) per capita

$b_{1}=\mathrm{GHGs}$, tons per capita

$x_{1}=$ energy consumption, GJ per capita

$x_{2}=$ labor, number of workers per capita

$x_{3}=$ capital, 1000 Euro (1995 constant price) per capita 
Table 3 Descriptive statistics for variables in the output distance function; mean and standard deviations (in parentheses)

\begin{tabular}{|l|c|c|c|c|c|}
\hline \multirow{2}{*}{ Country } & \multicolumn{5}{|c|}{ Variable } \\
\cline { 2 - 6 } & $y_{1}$ & $b_{1}$ & $x_{1}$ & $x_{2}$ & $x_{3}$ \\
\hline \multirow{2}{*}{ Austria } & 23.46 & 9.82 & 114.13 & 0.46 & 75.70 \\
& $(1.24)$ & $(0.18)$ & $(4.49)$ & $(0.00)$ & $(4.47)$ \\
\hline \multirow{2}{*}{ Belgium } & 21.12 & 14.83 & 144.01 & 0.38 & 55.26 \\
& $(1.33)$ & $(0.29)$ & $(6.86)$ & $(0.01)$ & $(3.82)$ \\
\hline \multirow{2}{*}{ Denmark } & 26.45 & 14.71 & 116.48 & 0.50 & 79.58 \\
& $(1.85)$ & $(1.21)$ & $(2.76)$ & $(0.01)$ & $(2.12)$ \\
\hline \multirow{2}{*}{ Finland } & 20.52 & 14.89 & 185.40 & 0.44 & 65.63 \\
& $(2.07)$ & $(0.55)$ & $(9.50)$ & $(0.03)$ & $(1.16)$ \\
\hline \multirow{2}{*}{ France } & 20.35 & 9.34 & 102.14 & 0.37 & 60.49 \\
& $(1.00)$ & $(0.26)$ & $(2.68)$ & $(0.01)$ & $(2.78)$ \\
\hline \multirow{2}{*}{ Germany } & 23.38 & 12.93 & 113.19 & 0.44 & 82.38 \\
& $(0.89)$ & $(0.61)$ & $(2.18)$ & $(0.01)$ & $(4.18)$ \\
\hline \multirow{2}{*}{ Greece } & 8.88 & 10.93 & 65.59 & 0.37 & 39.47 \\
& $(0.60)$ & $(0.74)$ & $(5.33)$ & $(0.01)$ & $(2.85)$ \\
\hline \multirow{2}{*}{ Ireland } & 15.02 & 16.17 & 94.93 & 0.37 & 42.69 \\
& $(3.45)$ & $(0.90)$ & $(11.16)$ & $(0.05)$ & $(3.81)$ \\
\hline \multirow{2}{*}{ Italy } & 14.93 & 9.15 & 86.68 & 0.36 & 47.99 \\
& $(0.66)$ & $(0.23)$ & $(3.52)$ & $(0.01)$ & $(1.92)$ \\
\hline \multirow{2}{*}{ Luxembourg } & 35.24 & 21.87 & 346.12 & 0.41 & 61.15 \\
& $(4.09)$ & $(7.32)$ & $(29.30)$ & $(0.01)$ & $(6.23)$ \\
\hline \multirow{2}{*}{ Netherlands } & 20.99 & 14.35 & 128.24 & 0.45 & 66.08 \\
& $(1.67)$ & $(0.40)$ & $(4.90)$ & $(0.02)$ & $(2.89)$ \\
\hline \multirow{2}{*}{ Portugal } & 8.61 & 7.39 & 57.50 & 0.46 & 19.92 \\
& $(0.78)$ & $(0.65)$ & $(7.77)$ & $(0.01)$ & $(2.36)$ \\
\hline \multirow{2}{*}{ Spain } & 11.72 & 8.18 & 69.71 & 0.32 & 33.98 \\
& $(0.97)$ & $(0.78)$ & $(6.99)$ & $(0.02)$ & $(3.41)$ \\
\hline & 21.82 & 8.15 & 155.15 & 0.47 & 60.52 \\
& $(1.68)$ & $(0.24)$ & $(4.75)$ & $(0.03)$ & $(0.82)$ \\
\hline \multirow{2}{*}{ Sweden } & 14.90 & 11.89 & 103.90 & 0.45 & 42.28 \\
& $(0.66)$ & $(2.66)$ & $(0.01)$ & $(1.92)$ \\
\hline
\end{tabular}

$y_{1}=$ GDP, 1000 Euro (1995 constant price) per capita

$b_{1}=$ GHGs, tons per capita

$x_{1}=$ energy consumption, GJ per capita

$x_{2}=$ labor, number of workers per capita

$x_{3}=$ capital, 1000 Euro (1995 constant price) per capita 
Table 4 Descriptive statistics for variables explaining burden-sharing; mean and standard deviations (in parentheses), $c_{1}$ to $c_{10}$ defined at end of table

\begin{tabular}{|c|c|c|c|c|c|c|}
\hline \multirow[t]{2}{*}{ Country } & \multicolumn{6}{|c|}{ Variable } \\
\hline & $c_{1}$ & $c_{2}$ & $c_{3}$ & $c_{4}$ & $c_{5}$ & $c_{6}$ \\
\hline Austria & 26.77 & $\begin{array}{c}0.22 \\
(0.01)\end{array}$ & $\begin{array}{c}6.33 \\
(0.57) \\
\end{array}$ & $\begin{array}{c}0.41 \\
(0.01) \\
\end{array}$ & $\begin{array}{c}0.189 \\
(0.005)\end{array}$ & $\begin{array}{c}0.121 \\
(0.007)\end{array}$ \\
\hline Belgium & 23.86 & $\begin{array}{c}0.22 \\
(0.01) \\
\end{array}$ & $\begin{array}{l}10.98 \\
(0.54) \\
\end{array}$ & $\begin{array}{c}0.48 \\
(0.01) \\
\end{array}$ & $\begin{array}{c}0.166 \\
(0.006) \\
\end{array}$ & $\begin{array}{c}0.008 \\
(0.001) \\
\end{array}$ \\
\hline Denmark & 24.90 & $\begin{array}{c}0.18 \\
(0.00)\end{array}$ & $\begin{array}{c}5.08 \\
(0.25) \\
\end{array}$ & $\begin{array}{c}0.49 \\
(0.01)\end{array}$ & $\begin{array}{c}0.183 \\
(0.002) \\
\end{array}$ & $\begin{array}{c}0.041 \\
(0.002) \\
\end{array}$ \\
\hline Finland & 18.55 & $\begin{array}{c}0.24 \\
(0.02) \\
\end{array}$ & $\begin{array}{l}17.27 \\
(1.14) \\
\end{array}$ & $\begin{array}{c}0.35 \\
(0.02) \\
\end{array}$ & $\begin{array}{c}0.251 \\
(0.008) \\
\end{array}$ & $\begin{array}{c}0.168 \\
(0.018) \\
\end{array}$ \\
\hline France & 24.51 & $\begin{array}{c}0.19 \\
(0.00) \\
\end{array}$ & $\begin{array}{c}6.66 \\
(0.45) \\
\end{array}$ & $\begin{array}{c}0.48 \\
(0.01) \\
\end{array}$ & $\begin{array}{c}0.204 \\
(0.008) \\
\end{array}$ & $\begin{array}{c}0.071 \\
(0.006) \\
\end{array}$ \\
\hline Germany & 23.23 & $\begin{array}{c}0.24 \\
(0.01)\end{array}$ & $\begin{array}{c}5.53 \\
(0.20)\end{array}$ & $\begin{array}{c}0.47 \\
(0.01)\end{array}$ & $\begin{array}{c}0.174 \\
(0.006)\end{array}$ & $\begin{array}{c}0.015 \\
(0.004)\end{array}$ \\
\hline Greece & 13.75 & $\begin{array}{c}0.13 \\
(0.01) \\
\end{array}$ & $\begin{array}{l}14.18 \\
(0.74) \\
\end{array}$ & $\begin{array}{c}0.69 \\
(0.01) \\
\end{array}$ & $\begin{array}{c}0.181 \\
(0.008) \\
\end{array}$ & $\begin{array}{c}0.061 \\
(0.004) \\
\end{array}$ \\
\hline Ireland & 19.90 & - & - & $\begin{array}{c}0.60 \\
(0.04) \\
\end{array}$ & $\begin{array}{c}0.159 \\
(0.007) \\
\end{array}$ & $\begin{array}{c}0.015 \\
(0.003) \\
\end{array}$ \\
\hline Italy & 19.53 & $\begin{array}{c}0.23 \\
(0.00)\end{array}$ & $\begin{array}{c}7.92 \\
(0.20) \\
\end{array}$ & $\begin{array}{c}0.46 \\
(0.01)\end{array}$ & $\begin{array}{c}0.177 \\
(0.004)\end{array}$ & $\begin{array}{c}0.032 \\
(0.004)\end{array}$ \\
\hline Luxembourg & 38.78 & $\begin{array}{c}0.16 \\
(0.01)\end{array}$ & $\begin{array}{l}26.00 \\
(8.75) \\
\end{array}$ & $\begin{array}{c}0.55 \\
(0.05) \\
\end{array}$ & $\begin{array}{c}0.122 \\
(0.017)\end{array}$ & $\begin{array}{c}0.005 \\
(0.0002) \\
\end{array}$ \\
\hline Netherlands & 21.45 & $\begin{array}{c}0.20 \\
(0.01)\end{array}$ & $\begin{array}{c}8.30 \\
(0.50) \\
\end{array}$ & $\begin{array}{c}0.31 \\
(0.01) \\
\end{array}$ & $\begin{array}{c}0.152 \\
(0.008) \\
\end{array}$ & $\begin{array}{c}0.006 \\
(0.0004) \\
\end{array}$ \\
\hline Portugal & 11.33 & $\begin{array}{c}0.22 \\
(0.01)\end{array}$ & $\begin{array}{l}10.44 \\
(0.50) \\
\end{array}$ & $\begin{array}{c}0.62 \\
(0.01) \\
\end{array}$ & $\begin{array}{c}0.186 \\
(0.005) \\
\end{array}$ & $\begin{array}{c}0.132 \\
(0.014)\end{array}$ \\
\hline Spain & 16.40 & $\begin{array}{c}0.22 \\
(0.00) \\
\end{array}$ & $\begin{array}{c}8.82 \\
(0.21) \\
\end{array}$ & $\begin{array}{c}0.61 \\
(0.01) \\
\end{array}$ & $\begin{array}{c}0.193 \\
(0.007) \\
\end{array}$ & $\begin{array}{c}0.054 \\
(0.006) \\
\end{array}$ \\
\hline Sweden & 21.64 & $\begin{array}{c}0.22 \\
(0.02) \\
\end{array}$ & $\begin{array}{l}12.16 \\
(1.61) \\
\end{array}$ & $\begin{array}{c}0.37 \\
(0.01) \\
\end{array}$ & $\begin{array}{c}0.326 \\
(0.011) \\
\end{array}$ & $\begin{array}{c}0.151 \\
(0.005) \\
\end{array}$ \\
\hline$U . K$. & 18.43 & $\begin{array}{c}0.24 \\
(0.01)\end{array}$ & $\begin{array}{c}7.39 \\
(0.27) \\
\end{array}$ & $\begin{array}{c}0.43 \\
(0.01) \\
\end{array}$ & $\begin{array}{c}0.175 \\
(0.005)\end{array}$ & $\begin{array}{c}0.004 \\
(0.001)\end{array}$ \\
\hline
\end{tabular}


Table 4 (continued)

\begin{tabular}{|c|c|c|c|c|}
\hline \multirow[t]{2}{*}{ Country } & \multicolumn{4}{|c|}{ Variable } \\
\hline & $c_{7}$ & $c_{8}$ & $c_{9}$ & $c_{10}$ \\
\hline Austria & -2.98 & $\begin{array}{c}8.06 \\
(0.02)\end{array}$ & 3.88 & 6.60 \\
\hline Belgium & 0.32 & $\begin{array}{l}10.11 \\
(0.08)\end{array}$ & 0.62 & 5.30 \\
\hline Denmark & -1.78 & $\begin{array}{c}5.22 \\
(0.07)\end{array}$ & 0.42 & 8.20 \\
\hline Finland & -7.58 & $\begin{array}{c}5.09 \\
(0.06)\end{array}$ & 23.00 & 8.60 \\
\hline France & 1.42 & $\begin{array}{l}59.17 \\
(0.70)\end{array}$ & 16.87 & 6.60 \\
\hline Germany & -0.88 & $\begin{array}{l}81.62 \\
(0.53)\end{array}$ & 10.74 & 6.60 \\
\hline Greece & 6.12 & $\begin{array}{l}10.40 \\
(0.12)\end{array}$ & 6.51 & 8.30 \\
\hline Ireland & 0.02 & $\begin{array}{c}3.61 \\
(0.08) \\
\end{array}$ & 0.61 & 6.80 \\
\hline Italy & 4.12 & $\begin{array}{l}57.39 \\
(0.22)\end{array}$ & 9.86 & 7.90 \\
\hline Luxembourg & -0.58 & $\begin{array}{c}0.41 \\
(0.02)\end{array}$ & 0.09 & 3.70 \\
\hline Netherlands & -0.08 & $\begin{array}{l}15.40 \\
(0.28)\end{array}$ & 0.38 & 6.40 \\
\hline Portugal & 5.82 & $\begin{array}{c}9.92 \\
(0.04)\end{array}$ & 3.24 & 9.90 \\
\hline Spain & 4.02 & $\begin{array}{l}39.19 \\
(0.24)\end{array}$ & 25.98 & 8.50 \\
\hline Sweden & -7.18 & $\begin{array}{r}8.76 \\
(0.11) \\
\end{array}$ & 28.01 & 9.00 \\
\hline$U . K$. & -0.88 & $\begin{array}{l}58.52 \\
(0.63)\end{array}$ & 2.47 & 5.90 \\
\hline
\end{tabular}




\section{List of variables in Table 4}

Standard of living characteristic

$c_{1}=$ Consumption expenditure (per household in 1000 Euro for 1994)

Economic structure characteristic

$c_{2}=$ Industry gross-value added as a share of GDP

Energy efficiency characteristic

$c_{3}=$ Industry energy intensity (industry's final energy consumption divided by industry gross-value-added; in GJ per billions of Euro)

Fuel mix characteristics

$c_{4}=$ Oil share (share of crude oil and petroleum consumption in final energy consumption)

$c_{5}=$ Electricity share (share of electricity consumption in final energy consumption)

$c_{6}=$ Renewable share (share of renewable energy sources in final energy consumption)

Climate characteristic

$c_{7}=$ Temperature (deviation of average temperature from the EU average temperature for the period 1964-1990)

Population size characteristic

$c_{8}=$ Population (in millions of inhabitants)

Additional characteristics

$c_{9}=$ Forest land (in millions of ha wooded area in 1995)

$c_{10}=$ Car age (average age of total number of cars) 
Table 5 Parameter estimates of output distance functions estimated on mean normalized variables

\begin{tabular}{|c|c|c|c|}
\hline Coefficient & Variable & $\begin{array}{c}\text { COLS } \\
\text { Estimate (t-value) }\end{array}$ & $\begin{array}{c}\text { LP } \\
\text { Estimate }\end{array}$ \\
\hline$\alpha_{0}$ & intercept & $1.79(6.65)^{*}$ & 1.77 \\
\hline$\alpha_{1}$ & $x_{1}$ & $-1.09(-3.67)^{*}$ & -0.50 \\
\hline$\alpha_{2}$ & $x_{2}$ & $0.53(1.10)$ & -0.02 \\
\hline$\alpha_{3}$ & $x_{3}$ & $-0.95(-2.56)^{*}$ & -0.43 \\
\hline$\beta_{1}$ & $y_{1}$ & $-1.11(-4.37)^{*}$ & -1.54 \\
\hline$\gamma_{1}=\beta_{1}+1$ & $b_{1}$ & $-0.11(-0.42)$ & -0.54 \\
\hline$\alpha_{11}$ & $x_{1} x_{1}$ & $0.20(1.10)$ & -0.04 \\
\hline$\alpha_{12}$ & $x_{1} x_{2}$ & $-0.13(-0.55)$ & 0.09 \\
\hline$\alpha_{13}$ & $x_{1} x_{3}$ & $1.33(7.69)^{*}$ & 0.66 \\
\hline$\delta_{11}$ & $x_{1} y_{1}$ & $-0.23(-1.69)$ & -0.10 \\
\hline$\eta_{11}=\delta_{11}$ & $x_{1} b_{1}$ & $-0.23(-1.69)$ & -0.10 \\
\hline$\alpha_{22}$ & $x_{2} x_{2}$ & $-0.92(-1.70)$ & -0.90 \\
\hline$\alpha_{23}$ & $x_{2} x_{3}$ & $-0.56(-1.60)$ & -0.42 \\
\hline$\delta_{21}$ & $x_{2} y_{1}$ & $0.85(4.95)^{*}$ & 0.80 \\
\hline$\eta_{21}=\delta_{21}$ & $x_{2} b_{1}$ & $0.85(4.95)^{*}$ & 0.80 \\
\hline$\alpha_{33}$ & $x_{3} x_{3}$ & $0.88(3.11)^{*}$ & -0.05 \\
\hline$\delta$ & $x_{3} y_{1}$ & $-0.54(-2.81)^{*}$ & 0.12 \\
\hline$\eta_{31}=\delta_{31}$ & $x_{3} b_{1}$ & $-0.54(-2.81)^{*}$ & 0.12 \\
\hline$\beta_{11}$ & $y_{1} y_{1}$ & $0.14(1.05)$ & -0.02 \\
\hline$\mu_{11}=\beta_{11}$ & $y_{1} b_{1}$ & $0.14(1.05)$ & -0.02 \\
\hline$\gamma_{11}=\beta_{11}$ & $b_{1} b_{1}$ & $0.14(1.05)$ & -0.02 \\
\hline$\kappa_{2}$ & Belgium & $-0.12(-3.09)^{*}$ & -0.11 \\
\hline$\kappa_{3}$ & Denmark & $0.05(1.29)$ & -0.04 \\
\hline$\kappa_{4}$ & Spain & $-0.72(-9.79)^{*}$ & -0.53 \\
\hline$\kappa_{5}$ & Finland & $-0.25(-5.13)^{*}$ & -0.27 \\
\hline$\kappa_{6}$ & France & $-0.08(-2.54)^{*}$ & -0.07 \\
\hline$\kappa_{7}$ & $U . K$. & $-0.61(-10.30)^{*}$ & -0.41 \\
\hline$\kappa_{8}$ & Germany & $0.04(1.51)$ & -0.07 \\
\hline$\kappa_{g}$ & Greece & $-0.87(-12.63)^{*}$ & -0.66 \\
\hline$\kappa_{10}$ & Ireland & $-0.64(-8.60)^{*}$ & -0.41 \\
\hline$\kappa_{11}$ & Italy & $-0.45(-8.55)^{*}$ & -0.33 \\
\hline$\kappa_{12}$ & Luxembourg & $0.53(4.69)^{*}$ & 0.52 \\
\hline$\kappa_{13}$ & Netherlands & $-0.20(-10.28)^{*}$ & -0.22 \\
\hline$\kappa_{14}$ & Portugal & $-1.21(-9.39)^{*}$ & -0.73 \\
\hline$\kappa_{15}$ & Sweden & $-0.09(-1.85)$ & -0.05 \\
\hline$\tau_{2}$ & 1991 & $0.01(1.59)$ & -0.01 \\
\hline$\tau_{3}$ & 1992 & $0.03(3.24)^{*}$ & -0.002 \\
\hline$\tau_{4}$ & 1993 & $0.04(4.21)^{*}$ & -0.005 \\
\hline$\tau_{5}$ & 1994 & $0.07(6.32)^{*}$ & 0.02 \\
\hline$\tau_{6}$ & 1995 & $0.09(7.59)^{*}$ & 0.03 \\
\hline$\tau_{7}$ & 1996 & $0.10(7.50)^{*}$ & 0.04 \\
\hline$\tau_{8}$ & 1997 & $0.14(9.47)^{*}$ & 0.06 \\
\hline$\tau_{9}$ & 1998 & $0.17(10.45)^{*}$ & 0.09 \\
\hline$\tau_{10}$ & 1999 & $0.19(11.02)^{*}$ & 0.11 \\
\hline & 2000 & $0.23(11.77)^{*}$ & 0.15 \\
\hline \multicolumn{2}{|c|}{ Adjusted R-squared } & 0.99 & \\
\hline \multicolumn{2}{|c|}{ Number of observations } & 156 & 156 \\
\hline
\end{tabular}

* Denotes significance at 5\% level. 
Table 6 Technical output efficiency scores, and potential output changes in percentage (standard deviations in parentheses)

\begin{tabular}{|l|c|c|c|c|c|c|}
\hline \multirow{2}{*}{ Country } & \multicolumn{3}{|c|}{ COLS } & \multicolumn{3}{c|}{ LP } \\
\cline { 2 - 7 } & $\begin{array}{c}\text { CD } \\
\text { Mean } \\
\text { normalized }\end{array}$ & $\begin{array}{c}\Delta \text { GDP } \\
\% \text { cap }\end{array}$ & $\begin{array}{c}\Delta \text { GHG } \\
\% / \text { cap }\end{array}$ & $\begin{array}{c}\text { Mean } \\
\text { normalized }\end{array}$ & $\begin{array}{c}\Delta \text { GDP } \\
\% / \text { cap }\end{array}$ & $\begin{array}{c}\Delta \text { GHG } \\
\% / \text { cap }\end{array}$ \\
\hline Austria & $0.06(0.01)$ & 4.88 & -7.59 & $0.02(0.01)$ & 1.63 & -2.53 \\
\hline Belgium & $0.06(0.02)$ & 5.42 & -5.02 & $0.02(0.02)$ & 1.81 & -1.68 \\
\hline Denmark & $0.06(0.03)$ & 4.33 & -5.07 & $0.05(0.04)$ & 3.61 & -4.22 \\
\hline Finland & $0.06(0.02)$ & 5.58 & -5.00 & $0.03(0.02)$ & 2.79 & -2.50 \\
\hline France & $0.06(0.01)$ & 5.63 & -7.98 & $0.01(0.01)$ & 0.94 & -1.33 \\
\hline Germany & $0.06(0.01)$ & 4.90 & -5.76 & $0.01(0.01)$ & 0.82 & -0.96 \\
\hline Greece & $0.06(0.02)$ & 12.89 & -6.82 & $0.02(0.02)$ & 4.30 & -2.27 \\
\hline Ireland & $0.06(0.02)$ & 7.62 & -4.61 & $0.04(0.04)$ & 5.08 & -3.07 \\
\hline Italy & $0.06(0.02)$ & 7.67 & -8.14 & $0.02(0.02)$ & 2.56 & -2.71 \\
\hline Luxembourg & $0.06(0.02)$ & 3.25 & -3.41 & $0.03(0.03)$ & 1.62 & -1.70 \\
\hline Netherlands & $0.06(0.03)$ & 5.45 & -5.19 & $0.02(0.02)$ & 1.82 & -1.73 \\
\hline Portugal & $0.06(0.02)$ & 13.30 & -10.08 & $0.01(0.01)$ & 2.22 & -1.68 \\
\hline Spain & $0.06(0.02)$ & 9.77 & -9.11 & $0.01(0.02)$ & 1.63 & -1.52 \\
\hline Sweden & $0.06(0.01)$ & 5.25 & -9.14 & $0.02(0.01)$ & 1.75 & -3.05 \\
\hline U.K. & $0.06(0.02)$ & 7.68 & -6.27 & $0.02(0.02)$ & 2.56 & -2.09 \\
\hline Average & $0.06(0.02)$ & 6.00 & -6.00 & $0.02(0.02)$ & 2.00 & -2.00 \\
\hline At mean & 0.004 & 0.40 & -0.40 & 0.002 & 0.20 & -0.20 \\
\hline
\end{tabular}


Table 7 MACs (standard deviations in parentheses)

\begin{tabular}{|l|c|c|}
\hline Country & $\begin{array}{c}\text { MAC (COLS) } \\
\text { Price of 1 ton GHGs in GDP } \\
(1000 \text { Euro) }\end{array}$ & $\begin{array}{c}\text { MAC (LP) } \\
\text { Price of 1 ton GHGs in GDP } \\
(1000 \text { Euro) }\end{array}$ \\
\hline Austria & $0.27(0.09)$ & $0.94(0.04)$ \\
\hline Belgium & $0.31(0.05)$ & $0.28(0.05)$ \\
\hline Denmark & $0.59(0.05)$ & $1.36(0.10)$ \\
\hline Finland & $0.20(0.13)$ & $0.56(0.19)$ \\
\hline France & $0.22(0.06)$ & $0.39(0.03)$ \\
\hline Germany & $0.15(0.09)$ & $0.87(0.05)$ \\
\hline Greece & $0.71(0.05)$ & $0.34(0.03)$ \\
\hline Ireland & $0.80(0.26)$ & $0.29(0.19)$ \\
\hline Italy & $0.37(0.03)$ & $0.29(0.02)$ \\
\hline Luxembourg & $0.04(0.05)$ & $0.06(0.05)$ \\
\hline Netherlands & $0.49(0.07)$ & $0.79(0.18)$ \\
\hline Portugal & $3.32(0.37)$ & $0.79(0.09)$ \\
\hline Spain & $0.56(0.09)$ & $0.14(0.07)$ \\
\hline Sweden & $0.43(0.17)$ & $0.80(0.23)$ \\
\hline U.K. & $1.25(0.12)$ & $0.71(0.07)$ \\
\hline Average & $0.67(0.80)$ & $0.57(0.36)$ \\
\hline At mean & 0.49 & 0.51 \\
\hline
\end{tabular}


Table 8 Analysis of the BSA ( $\mathrm{t}$-values within parentheses)

\begin{tabular}{|l|l|c|c|}
\hline \multirow{2}{*}{ Coefficient } & \multirow{2}{*}{ Variable } & \multicolumn{2}{|c|}{ Estimate (t-value) } \\
\cline { 3 - 4 } & & COLS & LP \\
\hline$\phi$ & Intercept & $71.44(10.85)^{*}$ & $62.17(10.00)^{*}$ \\
\hline$\omega$ & MAC for GHGS & $4.08(5.68)^{*}$ & $10.98(3.69)^{*}$ \\
\hline$\zeta_{1}$ & Consumption expenditure & $-1.71(-29.78)^{*}$ & $-1.84(-25.62)^{*}$ \\
\hline$\zeta_{2}$ & $\begin{array}{l}\text { Industry gross value added, } \\
\text { as a share of GDP }\end{array}$ & $-75.90(-7.31)^{*}$ & $-28.23(-3.29)^{*}$ \\
\hline$\zeta_{3}$ & Industry energy intensity & $-0.04(-0.93)$ & $0.19(3.62)^{*}$ \\
\hline$\zeta_{4}$ & Oil share & $-17.52(-4.80)^{*}$ & $-13.04(-3.33)^{*}$ \\
\hline$\zeta_{5}$ & Electricity share & $71.26(6.12)^{*}$ & $89.03(6.32)^{*}$ \\
\hline$\zeta_{7}$ & Renewable share & $86.19(15.93)^{*}$ & $100.28(13.45)^{*}$ \\
\hline$\zeta_{8}$ & Temperature & $2.67(17.62)^{*}$ & $3.45(19.55)^{*}$ \\
\hline$\rho_{1}$ & Population & $-0.21(-15.54)^{*}$ & $-0.23(-15.10)^{*}$ \\
\hline$\rho_{2}$ & Forest land & $0.69(14.22)^{*}$ & $0.72(10.66)^{*}$ \\
\hline Adjusted R-squared & $-4.79(-15.00)^{*}$ & $-5.99(-9.97)^{*}$ \\
\hline Number of observations & 0.99 & 0.99 \\
\hline
\end{tabular}

* Denotes significance at $5 \%$ level. Due to lack of data, the number of observations is now less. Ireland lacked data on gross-value added for the industry and is, therefore, excluded from the estimations. In addition, other countries lacked data on other variables for certain years. For instance, there is no observation on Road freight transport for the year 2000. Therefore, the BSA analysis covers the period 1990-1999. 


\section{Appendix}

\section{Linear Programming}

As in Färe et al. (2005) the parametric estimation of the quadratic directional output distance function in (4) is first performed by following Aigner and Chu (1968). Specifically, by assuming the directional vector $g=\left(g_{y_{1}}=1,-g_{b_{1}}=-1\right)$ the parameters in (4) are chosen to

$$
\operatorname{minimize} \sum_{k=1}^{K} \sum_{t=1}^{T}\left[D^{k t}\left(x^{k t}, y^{k t}, b^{k t} ; 1,-1\right)-0\right]
$$

subject to

$$
\begin{aligned}
& D^{k t}\left(x^{k t}, y^{k t}, b^{k t} ; 1,-1\right) \geq 0, \quad k=1, \ldots, K, \quad t=1, \ldots, T \\
& D^{k t}\left(x^{k t}, y^{k t}, 0 ; 1,-1\right)<0, \quad k=1, \ldots, K, \quad t=1, \ldots, T \\
& \frac{\partial D^{k t}\left(x^{k t}, y^{k t}, b^{k t} ; 1,-1\right)}{\partial y_{1}} \leq 0, \quad k=1, \ldots, K, \quad t=1, \ldots, T \\
& \frac{\partial D^{k t}\left(x^{k t}, y^{k t}, b^{k t} ; 1,-1\right)}{\partial b_{1}} \geq 0, \quad k=1, \ldots, K, \quad t=1, \ldots, T \\
& \frac{\partial D^{k t}(\bar{x}, \bar{y}, \bar{b} ; 1,-1)}{\partial x_{n}} \geq 0, \quad n=1, \ldots, N
\end{aligned}
$$

To ensure that the functional form of the distance function in (4) satisfies desirable properties, the minimization problem in (A1) is solved subject to restrictions (i) (vii). The restrictions in (i) constrain each producer to operate on, or below, the technological frontier. The null-jointness property is imposed by the restrictions in (ii). This means that, for $y>0$, the output bundle $(y, 0)$ is not technically feasible, which then formally can be stated as $(y, 0) \notin P(x)$ if and only if $D(x, y, 0 ; g)<0$. 
Monotonicity in outputs is imposed by the restrictions in (iii) and (iv), which ensures the correct sign of the shadow prices to be calculated. Monotonicity in inputs is imposed by the restrictions in (v). To confine the number of constraints this is done at the mean level of data. The translation property in (2) is ensured by the restrictions in (vi) and, finally, the restrictions in (vii) impose symmetry.

\section{Corrected Ordinary Least Squares}

Following Färe et al. (2005) the parametric estimation of the quadratic directional output distance function in (4) is also performed using Corrected Ordinary Least Squares (COLS). The translation property in (2) can in our case be rewritten as

$$
D\left(x_{1}, x_{2}, x_{3}, y_{1}+\alpha \cdot g_{y_{1}}, b_{1}-\alpha \cdot g_{b_{1}} ; g\right)+\alpha=D\left(x_{1}, x_{2}, x_{3}, y_{1}, b_{1}\right),
$$

where $D\left(x_{1}, x_{2}, x_{3}, y_{1}, b_{1} ; g\right) \geq 0$, and $g_{y_{1}}=1$ and $-g_{b_{1}}=-1$. Hence,

$$
D\left(x_{1}, x_{2}, x_{3}, y_{1}+\alpha, b_{1}-\alpha ; g\right) \geq-\alpha,
$$

Letting $\alpha=b_{1}$, and introducing random variation, $\varepsilon$, gives

$$
-b_{1}=D\left(x_{1}, x_{2}, x_{3}, y_{1}+b_{1} ; g\right)+\varepsilon,
$$

and by specifying $D(\cdot)$ in (A4) as a quadratic function we get

$$
\begin{aligned}
-b_{1}^{k t} & =\alpha_{0}+\sum_{n=1}^{3} \alpha_{n} x_{n}^{k t}+\beta_{1}\left(y_{1}^{k t}+b_{1}^{k t}\right) \\
& +\frac{1}{2} \sum_{n=1}^{3} \sum_{n^{\prime}=1}^{3} \alpha_{n n^{\prime}} x_{n}^{k t} x_{n^{\prime}}^{k t}+\sum_{n=1}^{3} \delta_{n 1} x_{n}^{k t}\left(y_{1}^{k t}+b_{1}^{k t}\right) \\
& +\frac{1}{2} \beta_{11}\left(y_{1}^{k t}+b_{1}^{k t}\right)^{2} \\
& +\kappa_{k}+\tau_{t}+\varepsilon^{k t}
\end{aligned}
$$


which can be estimated by OLS. The resulting estimator can be used to obtain technical efficiency scores. By adding $\left(b_{1}^{k t}-\hat{\varepsilon}^{k t}\right)$ to both sides of the equality in (A5) and "correcting" the intercept by adding the largest residual, $\max (\varepsilon)$, we get the COLS technical efficiency scores estimator ${ }^{32}$

$$
\begin{aligned}
\hat{C D}^{k t}\left(x_{1}^{k t}, x_{2}^{k t}, x_{3}^{k t}, y_{1}^{k t}, b_{1}^{k t} ; g\right) & =\left(\hat{\alpha}_{0}+\max (\hat{\varepsilon})\right)+\sum_{n=1}^{3} \hat{\alpha}_{n} x_{n}^{k t}+\hat{\beta}_{1}\left(y_{1}^{k t}+b_{1}^{k t}\right) \\
& +\frac{1}{2} \sum_{n=1}^{3} \sum_{n^{\prime}=1}^{3} \hat{\alpha}_{n n^{\prime}} x_{n}^{k t} x_{n^{\prime}}^{k t}+\sum_{n=1}^{3} \hat{\delta}_{n 1} x_{n}^{k t}\left(y_{1}^{k t}+b_{1}^{k t}\right) \\
& +\frac{1}{2} \hat{\beta}_{11}\left(y_{1}^{k t}+b_{1}^{k t}\right)^{2} \\
& +\hat{\kappa}_{k}+\hat{\tau}_{t}+b_{1}^{k t}
\end{aligned}
$$

which is the expression to be differentiated when calculating shadow prices of outputs. The correction of the intercept results in the technical efficiency estimate $\hat{C D}(\cdot)$, which is nonnegative, corresponding to restrictions (i) in the optimization problem in (A1). Also, note that $\hat{C D}^{k t}(\cdot)=-\left(\hat{\varepsilon}^{k t}-\max (\hat{\varepsilon})\right)$.

\footnotetext{
${ }^{32}$ Regarding the COLS estimator, see, e.g., Greene (1993).
} 